\title{
Julio Herrera y Reissig: das margens ao cânone
}

\author{
Luciana Brandão Leal ${ }^{*}$ \\ Maria Luiza Leão**
}

\begin{abstract}
RESUMO
Este trabalho destaca alguns aspectos biográficos e opiniões de críticos renomados sobre sua obra de Julio Herrera y Reissig, uma vez que o poeta tornou-se uma referência obrigatória da literatura latino-americana de sua época. Para tanto, será ancorado em críticos como Guilhermo de Torre e Eduardo Espina, estudiosos da obra herreriana, entre outros.

Palavras-chave: Julio Herrera y Reissig. Literatura Latino-americana. Poesia.
\end{abstract}

De acordo com Guilhermo de Torre, em prefácio escrito para a publicação da obra de Julio Herrera y Reissig - Poesias completas (1942), não faltaram junto a Rubén Dario outras grandes figuras que se destacaram no modernismo latinoamericano como, por exemplo, Ricardo Jaimes Freyre, José Santos Chocano, Leopoldo Lugones, Amado Nervo, Guillermo Valencia e Enrique Gonzáles Martínez.

No entanto, há outra personalidade que, na opinião desse crítico, permaneceu quase sempre na sombra. Trata-se do uruguaio Julio Herrera y Reissig, cuja grandeza, sem dúvida, somente admite paridade com a de Rubén Dario. Com todos os riscos e os excessos de seu caminho, tantas e tantas rapsódias fáceis de despertar leitores, graças à exuberância de "tardes lilás", "gestos verdes", "sonrisas de color topacio" etc. Até a sua morte precoce evitou o movimento em direção a outras formas possíveis e fornece à obra uma harmoniosa unidade de coisa acabada.

Embora sua vida esteja em sua obra e sua biografia seja breve, necessário se faz resumir algumas características de sua vida.

Julio Herrera y Reissig nasceu em Montevidéu no dia 09 de janeiro de 1875.

" Pontifícia Universidade Católica de Minas Gerais - PUC Minas.

** Universidade Federal de Viçosa - UFV. 
Era oriundo de uma família "nativa", de destaque na política do país. No entanto, não teve privilégios. Exatamente no dia de seu nascimento, seu tio Julio Herrera y Obes, político atuante, juntamente com outros líderes, fora deportado, como forma de abortar uma revolução local. E como naquela época tudo era subordinado à política, o poeta respirou a atmosfera de fracasso e decadência do país. Apesar disso, recebeu educação burguesa. Pouco ou nada se sabe de sua infância e de sua adolescência, exceto que foi educado em um colégio religioso.

Ainda jovem, ele já possuía uma saúde ruim, por isso teve, aos dezessete anos, que abandonar seus estudos formais, devido a uma doença cardíaca congênita agravada quando contraiu febre tifoide. Esta circunstância impediu-o de realizar viagens longas, apenas uma para Bueno Aires, além de algumas poucas visitas a cidades interioranas do Uruguai.

Devido à doença, começou a usar morfina para controlar as palpitações e pulsações desordenadas que tinha. Para referir-se a sua incurável condição física, o poeta escreveu:

Por estes tempos enfermo. Eu não sei se em tom de brincadeira. Minha cama dança em cake-walk. Consoles, mesa de cabeceira, bordas, molduras, tudo em embriaguez mudava, gesticulando de um modo espírita. A ciência, digo, não salva, não pode salvar. Tenho um coração insensato, metafórico, que não é humano. Como ouço, fatalmente desenvolvido o órgão do amor... Memória... Coisa desconhecida! Precisarão de vinte médicos na hora exata deste acontecimento. (ESPINA, 2010, p. 86-7).

Quando tinha vinte anos, escreveu um discurso político sobre "herrerismo", que versava sobre a ruína econômica e a caída do prestígio social de sua família.

Somente um mês antes de morrer conseguiu um emprego estável como bibliotecário de uma universidade. Casou-se com Julieta de la Fuente, que soube ser fiel à sua memória. Doente desde sua juventude, faleceu em 18 de março de 1910, vítima de um ataque cardíaco.

Sua estreia literária coincide com as últimas chamas românticas:

É com Canto a Lamartine (1898), de "elevado estro", que o poeta maduro diz nunca ter pensado em incorporá-lo aos seus livros. Depois, com um projeto de lei similar, tem as suas restantes obras iniciais significativas, suas odes a España, a Castelar, a Guido Spano, concebidas sob a sombra hugoana. Acontece, porém, que a sua evolução é muito rápida. Em 1900, Herrera y Reissig já tinha escrito suas Pascuas del tiempo, além de traduções de Baudelaire e Samain, ente outros. (TORRE, 1942, p. 12). 
A partir de 1900, Herrera y Reissig conduzia reuniões literárias em sua mansão familiar em Montevidéu, conhecida como La Torre de Los Panoramas, por causa da vista que tinha para o rio da Prata. Viveu nessa mansão no período de 1901 a 1907 e fez dela uma das áreas de maior efervescência da cultura uruguaia do século XX.

Jan Más y Pi, escritor espanhol, grande amigo e primeiro apologista do poeta, disse que "La Torre de los Panoramas ficou conhecida tanto no Uruguai como no exterior porque lá tudo era realmente vivo". (TORRE, 1942, p. 14).

E Zum Felde acrescenta que:

Durante cinco anos de seu auge, participaram de encontros os tipos mais representativos do modernismo; e não passava visitante literário por Montevideu que não fosse levado àquele sótão... Ser tertuliano de La Torre era, em 1905, um sinal de louvor literário entre os jovens. (FELDE apud TORRE, 1942, p. 14).

Outro amigo fraterno de Herrera y Reissig, o escritor uruguaio César Miranda, em seu livro Prosa, fez a melhor descrição do cenário:

Aquela torre era simplesmente um sótão, quase decrépito, mal saindo do nível do telhado, as paredes decoradas com gravuras e fotografias mostravam o gosto e a pobreza da família. Um boné turco, um par de florzinhas emboroladas, uma pequena mesa e duas cadeiras velhas decoravam e completavam o mobiliário. Neste cenário pequeno e humilde, Florencio Sanches, pássaro de passagem, fez um ninho momentâneo no cubo de alvenaria, onde as rimas mais estranhas ecoaram, naquele quarto desmantelado foi desenvolvida a renovação literária do Uruguai. (MIRANDA apud TORRE, 1942, p. 14).

De acordo com Espina, com base nos testemunhos de César Miranda e Julieta de la Fuente, viúva do poeta, Magela Flores Mora resumiu as características de La Torre de los Panoramas em seu livro Julio Herrera y Reissig (Estudio Biográfico), de 1947:

O mobiliário comido pelas traças eram três cadeiras - tipo que só é encontrado na sacristia - uma mesa com três pernas de tamanho pequeno e uma chaise-longue de tapete puído. Ao entrar, a primeira coisa que vimos foi uma pintura sem um quadro, o ex-presidente Julio Herrera y Obes. Em cada parede, ou presa com tachas, tinha ilustrações de Gustave Dore, rasgadas de uma Bíblia da família, essas Bíblias tristes usadas para entreter as crianças com febre à noite. Respirava-se odor de umidade. Para chegar lá tinha que 
atravessar parte do telhado exposto ao vento do mar. Mas todos os problemas desapareciam ao contemplar o panorama inesperado e maravilhoso que era oferecido aos olhos espantados do tertuliano. (MORA apud ESPINA, 2010, p. 57).

Sobre as atividades literárias que se realizavam em torno do poeta anfitrião, Flores Mora escreveu:

Às cinco e meia da tarde começavam a chegar os tertulianos da Torre. Julio os recebia quase sempre recostados na chaise-longue, enrolado em uma manta velha. Geralmente a noite começava com uma aula de esgrima dirigida por Roberto de las Carreras. Então, liam versos, muitos dos quais eram improvisados. Conversavam sobre o último livro recente, criticavam-no e sonhavam muito. Julio bebia mate amargo e tocava durante horas guitarra. Ele desconhecia a harmonia e a teoria musical. Ele tocava o instrumento de ouvido, fazendo verdadeiras proezas. Era assim, ante os estupefatos tertulianos, que chegava uma ária de La Traviata, as fugas de Bach ou os últimos prelúdios de Chopin. A guitarra havia sido trazida de Valencia por um familiar e era para Julio tão indispensável quanto os remédios. (MORA apud ESPINA, 2010, p. 58).

Herrera y Reissig escreveu ficção, ensaios políticos, mas é fundamentalmente reconhecido por sua produção poética. Aí começa a evolução do romantismo à arte modernista que faria dele uma referência indispensável postumamente na poesia latino-americana do período, juntamente com Leopoldo Lugones, Ricardo Jaimes Freyre e Salvador Diaz Miron.

Sobre sua produção literária, Francisco Villaespesa foi o primeiro a reconhecer e elogiar, na Espanha, Herrera y Reissig. Em Montevidéu, Zum Felde criticou veementemente a mídia por tê-lo ignorado. E o próprio Herrera y Reissig, como réplica aos desaforos criticistas daqueles que o combatiam, publicou:

Decreto. Abomino a promiscuidade de catálogo. Sou eu comigo mesmo! Proclamo a imunidade de minha pessoa. Eu sou imperador. Me incomoda que certos cabeleireiros da crítica me façam a barba... Deixem em paz os Deuses! Eu, Julio. Torre de los Panoramas. (REISSIG apud TORRE, 1942, p. 16).

Rubén Dario afirmava que Herrera y Reissig era um homem de grande cultura, tanto moderna como clássica, mas que

Um crítico academizante de seu país, "Lauxar", quis pintá-lo como um ser ignorante. Do outro lado da Cordilheira, Norberto 
Pinnilla disse que Herrera y Reissig teve uma cuidadosa educação humanista e questiona a que opinião devemos nos ater, mas responde imediatamente que a nenhuma delas, porém a uma outra, a que interfere a estreita leitura dos textos do poeta. (DARIO apud TORRE. 1942 p. 17).

Em relação à estética, Herrera y Reissig foi um esteticista perfeito, um conhecedor apaixonado de toda literatura que o interessava para o crescimento de seu espírito. Suas leituras foram as de seu tempo, na qual, liricamente, o simbolismo francês dominava quase com exclusividade.

Poeta de extraordinária unidade, Julio Herrera depura e perfecciona seu estilo ao longo de dez anos de intensa produção, mantendo-se rigorosamente fiel a si mesmo. Em sua obra, segundo Torre, pode-se marcar dois momentos das fases capitais:

Uma de linha barroca, com intenções metafísicas, de fundo subconsciente e expressão por vezes obtusa, que começa com o poema La vida (1900), passa por Desolación absurda de Los Maitines de la noche (1902) e termina com a Tertulia lunática de La Torre de las Esfinges (1909). A outra fase é de caráter menos complexo, de inspiração pastoral, de tema idílico-eclógico, onde estão talvez seus poemas mais puros e de valor lírico, que começa com o poema Ciles alucinada (1903) para atingir sua plenitude no soneto Los éxtasis de la montaña (duas séries: 1904, 1910), nos Sonetos vascos (1906), e conhecer o declínio na segunda série de Los parques abandonados (1908). Além dos sonetos de amor da primeira série de Los parques abandonados (1901), a ampulheta exótica de Las clepsidras (1910) e a esplêndida peça final, Berceuse blanca (1910). (TORRE, 1942, p. 19).

O estudioso conclui que

São, por conseguinte, duas fases fundamentais: a pastoral ou idílico-eclógica, onde se encontra suas mais insólitas descobertas metafóricas; e a considerada decadente em virtude de seus temas, mas que prefiro chamar barroca por seu estilo, se não fosse sua visão expressionista. Nessas duas fases, Herrera y Reissig aparece como poeta perfeito e profundamente original. (TORRE, 1942, p. 19).

De acordo com Espina, com o passar do tempo, Herrera y Reissig "ultrapassou os marginalizados, o limiar que Dante cruzou na Divina Comédia, depois de visitar os círculos do inferno. Não há necessidade de pedir reconhecimento, sai de 
lá depois de décadas sem comer na mesa do rei”. (ESPINA, 2010, p. 14).

Em sua obra, a ênfase passou a ser na vitalidade das palavras para poder se expressar, encontrando alternativas naquilo que ainda não havia sido dito e que era a expressão mais proveniente que assumia na linguagem. Julio Herrera y Reissig inaugurou a modernidade poética.

Quando se comemorou, no ano de 1975, os cem anos de nascimento de Julio Herrera y Reissig, o governo uruguaio não sabia o que fazer, sobretudo porque Herrera não era um escritor como José Enrique Rodó, Florencio Sánchez ou Juana de Ibarbourou, facilmente transformável em uma figura oficial do governo, que pouco se importava com a cultura e a reconsideração histórica. A república Oriental do Uruguai, país cheio de paradoxos, acrescentou mais um a sua lista: a imagem de Herrera y Reissig fora redimensionada, alargada, pelo desprezo daqueles que tinham interrompido a vida democrática do país. O único jornal a informar sobre o centenário de nascimento de Herrera y Reissig foi El Día. Na página 12 da edição de 09 de janeiro de 1975, publicou um artigo intitulado: "El centenário del Nascimiento de Julio Herrera y Reissig", que detalhava a trajetória de vida do homenageado e nas entrelinhas inferia um pouco sobre a importância histórica que teve em seu país de origem. No dia 05 de junho do mesmo ano, El País publicou um fascículo especial dedicado especialmente ao centenário de Julio Herrera y Reissig, no qual se destaca um artigo da poetisa Clara Silva, crítica literária uruguaia renomada. De um modo geral, em vez de pompa oficial para comemorar o seu aniversário, o silêncio imperava em quase todos os lugares, com apenas poucas manifestações.

A história e a literatura não mantêm uma relação simétrica. $\mathrm{O}$ desinteresse do governo em nada afetou a consagração da obra herreriana,

Que se consagrou nos últimos trinta e cinco anos, de 1975 até hoje, seu lugar definitivo na história da literatura escrita em castelhano. Hoje, por conseguinte, a ocasião não tem tanto a ver com a recordação do centenário de morte do poeta, mas com a permanência de uma obra extraordinária em muitos aspectos aos acontecimentos históricos e políticos que a acompanharam no decorrer dos tempos, ganhando influência e ressonância, sem perder sua raridade, de tal forma que, por muito tempo apagada, tornou-se difícil classificá-la. (ESPINA, 2010, p. 13).

Em um país raro em muitos aspectos, também literariamente, sobretudo por ter produzido muitos escritores originais cujas obras incluídas hoje em dia resultam raridades inclassificáveis como, por exemplo, Horácio Quiroga, Delmira Agustine e Felisberto Hernández, Julio Herrera y Reissig representa uma realidade à parte, 
isto é, um caso único, principalmente porque estava à frente do tempo, embora nunca tivesse a intenção de dar lições de vanguarda, a sua poesia e os seus ensaios não param de se mover. Espina salienta que

Sylvia Molloy, crítica e romancista, sintetizou muito bem esta situação, quando questiona se havia pensado no Uruguai como terra privilegiada de raros precursores verdadeiramente originais, dizendo que, além de Lautreamont, cuja nacionalidade pode ser discutida, deve se pensar em Herrera y Reissig. (ESPINA, 2010, p. 13-4).

Mesmo com tanto descaso, a obra de Julio Herrera y Reissig ganhou o reconhecimento dos leitores, dentro e fora das fronteiras. Sua poesia não está mais sofrendo as ofensas e a estupidez dos leitores desatentos ou de compilações continentais excluídas, como a de Laurel: Antologia de la poesía moderna en lengua española (1941), cuja seleção foi conduzida por Octavio Paz, Emilio Prados, Juan Gil-Albert e Xavier Villaurrutia. Apesar de Laurel, figuram poetas menores e hoje quase esquecidos como Enrique González Martínez, José Moreno Villa e Bernardo Ortiz de Montellanos. Herrera y Reissig foi excepcionalmente excluído da longa lista. Aliás, entre os trinta e oito poetas antologados, não figura um uruguaio.

Octavio Paz, depois de algum tempo, desculpou-se pelo erro de julgamento. Referindo-se à crítica por ter excluído Herrera, o mexicano disse: "Eu não mereço censura por admirar o poeta, um dos meus favoritos, eu amei os sonetos de Los Parques Abandonados, mas logo descobri que estava enganando a sua originalidade". (PAZ apud ESPINA, 2010, p. 20).

Contudo, ele não foi o único mexicano que interpretou mal Herrera y Reissig. Alfonso Reyes, a quem Juana de Ibarbourou lhe deve a popularização de seu apelido "Juana de América", também o ignorou.

Em 1977, o crítico peruano Américo Ferrari comentou sobre o lento processo de reconhecimento pelo qual passou a obra de Herrera, sobretudo porque havia sido ignorada pelos modernistas mexicanos.

Em palestra publicada no jornal La Razon Montevideo em 24 de outubro de 1910, poucos meses depois de Herrera y Reissig morrer, o espanhol Francisco Villaespesa disse: "De todos os poetas latinos definitivos, Julio Herrera y Reissig era o menos conhecido, não só na Espanha, mas em seu próprio continente". (VILLAESPESA apud ESPINA, 2010, p. 20).

Sete meses antes, no obituário publicado no jornal El Tiempo de Montevideo, um dia após a morte do poeta, Victor Petit, referindo-se ao tratamento recebido por 
Herrera na vida literária, escreveu: "Dentro de alguns anos, quando relermos sua obra, compreenderemos que esse rapaz, desequilibrado e doente, possuía muito talento. Então, talvez, iremos experimentar remorso e vergonha." (PETIT apud ESPINA, 2010, p.20).

No entanto, como muitas vezes acontece, a obra ganhou a ignomínia, desatenção e leviandades de critérios das épocas, e, mais uma vez, Herrera y Reissig havia sido deixado de fora de uma amostra em caráter antológico. Convém lembrar que Wallace Stevens, quando estava escrevendo o melhor de sua obra poética, não o incluiu em Oxford Anthology of American Poetry. Este, o esquecimento injustificado, é tema muitas vezes repetido na literatura. Lamentavelmente, como a história cansa de demonstrar com reiterada sistematicidade, uma vez que a negligência nunca se torna obsoleta, a poesia que se lança precursora contra as normas estéticas de sua época encontra sérias dificuldades para ser aceita pelos leitores do momento histórico em que é produzida, e Herrera y Reissig não foi exceção.

Como se o desprezo tivesse sido muito pouco, antes e depois da crítica neutralizar suas conclusões formais falando com leviandade inaceitável, em termos supostamente rigorosos de "terra", "o sol", "à noite" ou "a lua" que compõem o núcleo central de sua poesia, Ferrari disse:

Vontade de poetizar livremente é o que fez de Herrera y Reissig um maestro, direta e indiretamente, para muitos dos grandes artistas hispano-americanos do nosso século. Deixou rastro em Sabat Ercasty que por sua vez influenciou Huidobro e Neruda; e a presença que imprimiu em Vallejo é mais que uma presença, uma marca ou uma cicatriz. Podemos dizer que no caso de Vallejo é ilustrativo; a influência de Herrera não é exercida apenas em Los heraldos negros, mas persiste aqui e ali em Poemas humanos. (FERRARI apud ESPINA, 2010, p. 22).

Embora a investida de uma nova escritura que traz o trabalho de Julio Herrera y Reissig seja inegável ponto de referência na atualidade, a ponta e a ligação, levou tempo para alcançar caráter indiscutível e ser vista com rigor historiográfico para, situada no contexto temporal de sua produção, ser impossível ignorar a participação generosa de sua originalidade. Parte requintada e revolucionária da obra desse poeta, como é o caso do poema "La Torre de las Esfinges", deve incluirse, por mérito próprio, na folha mais rigorosa de referentes canônicos da poesia latinoamericana. Tanto é verdade que, de acordo com Torre, 
A poesia de Herrera y Reissig transborda riquezas, algumas já mencionadas, outras quase sem precedentes, há muito passou despercebida ou desvalorizada. Somente nos últimos anos é que vem sendo capturada. Com satisfação e até mesmo - se me permitem - com um leve espírito de vangloriar-me, poderia lembrar que a "redescoberta" de Herrera y Reissig algum papel cabe a mim. Felizmente aconteceu de eu ler pela primeira vez na juventude plena, no momento de maior fevor, com uma sensibilidade fresca a todos os deslumbramentos e todas as exaltações. Depois, vieram às minhas mãos um volume de seus poemas selecionados que tinham acabado de publicar (Maucci, Barcelona) Ventura García Calderón. Li e reli apaixonadamente, contribuindo para tornar mais simpática a figura do poeta ardente, justificando o prólogo ardoroso e reivindicador de Juan Más y Pí. Imediatamente, compartilhei minha admiração aos colegas e professores de então. (TORRE, 1942, p. 29 - destaques do autor).

Herrera y Reissig pagou um excessivo tributo aos modos passageiros. Sua vontade, sua exuberância ou ânsia em acumular em certas poesias alguns elementos supostamente relacionados com o tema vieram à sua mente e recaíram na pompa decorativa, em excesso ornamental. Sofreu numerosos tics momentâneos, de excessivos adornos decadentes. Isso aconteceu em suas primeiras obras - como Las pascuas del tiempo - com seus inacabáveis e sobrecarregados desfiles, apesar de nunca se encontrar isento desses excessos.

Na verdade, essa acumulação, juntamente com a tensão angustiante de espírito, é o que o leva ao caminho barroco ou expressionista que se inicia em La vida, acentua-se em Tertulia lunática e culmina em Desolación absurda. É certo também que para julgar dessa maneira, a ótica deve ser distinta, porque a acumulação e a tensão parcelam muitas vezes o seu valor.

Vivem, ao contrário, na poesia de Herrera y Reissig vários outros elementos, sem dúvida, em sua maioria, mais formais do que espirituais. Além disso, ele previu em seu tempo as duas funções da linguagem, a lógica e a poética, quando escreveu: "No verso culto a palavra tem duas almas: uma de harmonia e a outra ideológica"; e também quando exclamou: "O verbo é tudo". (REISSIG apud TORRE, 1942, p. 32).

Assim, os vários valores para a regra deste dom verbal são oferecidos em sua poesia. Isso determina a sua riqueza imagética, suas metáforas inusitadas cheias de impulso mágico. Basta abrir Los extasis de la montaña para encontrar múltiplos exemplos. Poderiamos citar o soneto "El despertar", mas aqui, recolhidos aleatoriamente, algumas outras riquezas, a partir do mesmo livro: 
Los campos demacrados encanecen de frío

La joven brisa se despereza

(La velada)

(El alba)

En el dintel del cielo llamó por fin la esquila

Él ordeña la pródiga ubre de la nontaña

(Claroscuro)

Para encender con oros el po-bre altar de pino

Rayan el panorama como espectros agudos

(El cura)

Tres álamos en éxtasis...

Tirita entre algodones húedos la arboleda...

(La noche)

La cumbre está en u;n blanco éxtasis idealista...

Todo es grave... En las cañas el viento flautista

Te anuncia un ecuménico amasijo de hogaza

(El domingo)

Y la pradera huraña mira, en éxtasis verde,

Al monte que en el cielo enfosca un gesto oscuro

(Claroscuro)

Llovió... Trisca a los lejos un sol convaleciente

(El almuerzo)

(REISSIG apud TORRE, 1942, p. 32-33)

A visão herreriana da natureza ultrapassa a dos simbolistas, com uma exceção, a do poeta Saint-Pol Roux, cognominado El Magnífico, por seu dom criativo, que no final do século passado ofereceu imagens inesquecíveis. Assim, esta série de equivalências, desmembradas de distintos poemas:

Comadrona de la luz $=$ el gallo

Cementerio con alas $=$ vuelo de cuervos

Salmodiar el alejandrino de bronce $=$ sonar la medianoche

El gran aire puro $=$ coñac del padre Adán

Hojas de ensalada viva $=$ las ranas

Amapola sonora $=$ el canto del gallo

Rueca viva $=$ el cordero.

(REISSIG apud TORRES, 1942, p. 33).

A visão herreriana da natureza, superando o quadro do impressionismo pictórico, que dobrou os simbolistas, penetrava as fronteiras do expressionismo. Que significa exatamente o campo linguístico-literário, com independência da escola literária nomeada?

Expressionismo - disse uma autoridade científica nesses fenômenos do idioma - Elisa Richter - é a reprodução de representações ou 
sensações produzidas em nós por impressões externas ou internas, sem que entrem em consideração as propriedades reais dos objetos (de representação) que suscintam tais impressões. Oferece pensamento subjetivo e sentimento sobre as coisas: ideias de coisas presentes na presença especulativa. $\mathrm{O}$ artista expressionista não diz o que aocntece ou o que vê, mas o que move para o ponto de vista de um evento ou de uma coisa; expressa o seu sentimento pessoal e seu julgamento (às vezes, o preconceito) sobre as coisas. (TORRE, 1942, p. 33).

Bem, esse é o tipo de expressionismo praticado por Herrera y Reissig. Em sua poesia há todos os fenômenos correlatos do estilo. A coisa natural nunca aparece em suas formas, porém subjetivadas, tornam-se experiência íntima. A natureza surge humanizada, enquanto o inanimado se torna espiritualizado. Mais dois exemplos, a saber:

Y se durmió la tarde en tus ojeras

(La fuga, en Los parques abandonados)

Ríen los labios de leche

De los lucros precoces

Los astros tienen las mejillas tiernas

(Génesis, en Las clepsidras)

(REISSIG apud TORRE, 1942, p. 34).

Julio Herrera y Reissig acerta em corporizar as imagens mais abstratas e a abstrair o concreto. Abundância nas imagens olfativas, nas sinestesias ou na essência das representações de vários sentidos, nas vivificações e personificações; algo para preencher a maior lista de exemplos que podem compor uma crítica estilística - como ele tem feito desde Pino Saavedra. Isso sem mencionar os jogos de sonoridades imprevistas, de harmonias não utilizadas que por vezes sucede. Assim, um dos sonetos de Las clepsidras (Oblación abracadabra) é um gênero que só admite paridade com Gongora:

Lóbrega rosa que tu almizcle efluvías,

Y pitonisa de epilepsias libias,

Ofrendaste a Gonk-Gonk vísceras tibías

Y corazones de panteras nubias...

(REISSIG apud TORRE, 1942, p. 34-5).

Tanto em Las Clepsidras, que subtitula Cromos exóticos, como em Tertulia lunática de La Torre de las Esfinges, Herrera y Reissig atinge o limite máximo 
de sua tensão espiritual. É aí que as verdadeiras intenções da poesia pseudometafísica chegam ao limite máximo de sua tensão espiritual, mas envoltas na escuridão conceitual. Vale como exemplo a décima, que começa:

\author{
El cielo abre un gesto verde, \\ $\mathrm{Y}$ ríe desequilibrio \\ De un sátiro de ludibrio \\ Enfermo de absinto verde... \\ (REISSIG apud TORRE, 1942, p. 35).
}

Bucólico ou racional, eclógico ou inacessível, o universo nos poemas de Julio Herrera y Reissig ressurgem totalmente renovados e naturais, em seu rpimeiro princípio, em sua candura matinal ou seu crepúsculo de metamorfoses. Em suma, "aparece convertido em uma esfera comparada ao que miram nossos olhos no dia-adia, em uma esfera inteira e irredutivelmente poética.” (TORRE, 1942, p. 35).

Qualquer leitura atenta e minuciosa da obra lírica de Herrera y Reissig verifica uma performace linguística transformada por fase sintática, onde ocorre e entra na polifonia das regras incomuns. O poema é uma fatalidade embelezada que não tem como explicar a sua infinita ação; é uma exceção generalizada, uma aproximação associada a outras. Escrever as palavras ficou à beira de um solitário precipício, a voz completa, associada ao condensamento e à sonoridade propagada por entre os poemas, preserva o segredo que faz com que seja o ponto de partida de uma assimetria, e é melhor assim, porque uma vez alcançada a perfeição, em tanto artifício sem propósito, isso acaba entediante, resultando superficialmente falso. As palavras privilegiam o importunismo de tudo quanto parece inadequado. $\mathrm{O}$ poema não pretende ser melhor nem menos que isso. Sem alterar o seu catálogo de erros intencionais, que criam um efeito de colagem e sonoridade, entram em ação como um quebra-cabeça, com suas ressonâncias interrompidas, desvios, digressões e dispositivos interruptivos, criam um curtocircuito na cadência da sintaxis:

Tal como en una capilla

Ardiente de hiperestesia,

Entre grillos de anestesia,

Tiembla la noche en capilla...

Un gato negro en la orilla

Del cenador de bambú,

Telegrafía una cu

A Orión que le signa un guiño,

$Y$ al fin estrangula un niño

Inpromptu hereje en miaú!

(REISSIG apud ESPINA, 2010, p. 88). 
Com seu redundante hermetismo (como sempre prevalece uma estrutura rigorasamente montada em que se encontra uma persistente atividade de reescritura), o poema apresenta uma beleza intimidante que não se destina a satisfazer um espaço racional nem uma manifestação sentimental. Seus versos apostam no futuro imediato da primeira qualidade retórica e surpresa, sem demonstrar o menor interesse em querer agradar a um possível acolhimento ideal. As frases nunca são vazias de significado e estão incluídas em um entusiamo primário que as mantêm acordadas, despertas, mas alargando sua surpérflua mudança para algo prestes a ser completamente desconhecido. Nesse nomadismo sintático onde predominam diálogos carentes de argumentos e palavras que tenham sido entendidas a se transformarem em possibilidade frequente do pensamento, a língua tem grande oportunidade para ser diferente e não as perde.

Em um período literário caracterizado pela exaltação das emoções e da reprodução da realidade, a obra lírica e ensaíta de Herrera y Reissig passa a refletir o retorno do triunfal ao formidável. A linguagem celebra poderes de imaginação e rigor de ocultismo linguístico e também a utopia de representar o irrepresentável:

A anatomia espiritual do Ser e sua tentativa de infinito. Em sua travessia, a palavra poética rapidamente aprendeu a se rebelar contra qualquer praxi utilitária: "avança um grau na sombra". No entanto, como plano estático completo para planejar seus descobrimentos, esta obra não deve ser considerada uma destruição da praxis vital, mas uma transformação qualitativa dessa praxis, tranferida para o invólucro transcendente da palavra para as finalidades ontológicas e vitais que a ideologia predominante havia colocado no imediato e mundano. (ESPINA, 2010, p. 356-7).

Finalizando este trabalho, gostaríamos de salientar, amparadas pelas reflexões de Guilhermo Torre (1942) e Eduardo Espina (2010), que Julio Herrera y Reissig teve a passagem do tempo a seu favor e, somente depois de sua morte, ascendeu da sombra ao brilho, tornando-se um ponto de referência por sua maneira inigualável de fazer poesias. O poeta uruguaio, talvez involuntariamente, inaugurou o modernismo poético em língua espanhola; e sem fazer o menor esforço, trouxe a linguagem de uma literatura com frases sob medida, o que atualmente desperta nos críticos e leitores uma curiosidade associada ao espanto. 


\section{Abstract}

This work aim to highlight some biographical aspects and opinions of renowned critics of Julio Herrera y Reissig, since he became a reference in Latin American literature in his time. This work is anchored in critics such as Guillermo de Torre and Eduardo Espina, scholars in Herrera works, among others.

Keywords: Julio Herrera y Reissig. Latin american literature. Poetry.

Referências

ESPINA, Eduardo. Julio Herrera y Reissig. Montevideo: Uruguay, Editora Planeta S. A, 2010.

HERRERA y REISSIG, Julio. Julio Herrera y Reissig - Poesias completas. Bueno Aires: Uruguay. Ed. Losada S.A, 1942.

TORRE, Guilhermo de. Julio Herrera y Reissig - Poesias completas. Bueno Aires: Uruguay. Ed. Losada S.A, 1942. 
DOSSIÊ AFFONSO ÁVILA 